\title{
SIGNIFICANT INHIBITION OF THE TRIGGERING MECHANISM OF THE EXTRINSIC SYSTEM OF BLOOD COAGULATION IN RATS BY THYMUS PEPTIDES THYMULIN, THYMOSIN ALPHA 1 AND THYMOSIN BETA 4
}

\author{
Yuri Nyagolov $^{1}$, Kiril Hristozov ${ }^{2}$, Antoniya Hachmeryan ${ }^{3}$ \\ ${ }^{1}$ Department of Physiology, Medical University-Sofia \\ ${ }^{2}$ Department of Internal Diseases, Faculty of Medicine, Medical University of Varna \\ ${ }^{3}$ Department of Physiology and Pathophysiology, Faculty of Medicine, \\ Medical University of Varna
}

\begin{abstract}
INTRODUCTION: The role of the thymus gland and the effects of thymic peptides on the coagulation status are relatively insufficiently studied. Recent data indicate controversial and not persuasive results due to investigation of single hemostasis parameters and application of various pathological models.

AIM: The present study aimed to elucidate the influence of thymus peptides thymulin, thymosin alpha 1 and thymosin beta 4 applied s.c. on intact rats, on key triggering factors of blood coagulation via the extrinsic pathway: plasma concentration of tissue factor (TF); concentration and activity of free TFPI; and the activity of plasma clotting factor VII, as well as on prothrombin time (PT) - an integral clinical parameter of the intrinsic pathway.

MATERIALS AND METHODS: The study was performed on 52 male Wistar strain rats, weighing 200-220 g and bred under standard conditions at dark/light cycle $12 / 12 \mathrm{~h}$. The rats were divided into four equal groups $(\mathrm{n}=13)$ and injected s.c. once daily in the time interval 08.00-09.00 $\mathrm{h}$ in the course of three consecutive days as follows: 1st group (controls) - with saline (the solvent of the peptides); 2nd group - with thymulin (Sigma Aldrich, $0.4 \mathrm{mg} / \mathrm{kg} \mathrm{b.m.);} \mathrm{3rd} \mathrm{group} \mathrm{-} \mathrm{with} \mathrm{thymosin} \mathrm{alpha} 1$ (Sigma Aldrich, $0.3 \mathrm{mg} / \mathrm{kg} \mathrm{b.m.);} \mathrm{and} \mathrm{the} \mathrm{4th}$ group - with thymosin beta 4 (Sigma Aldrich, $0.3 \mathrm{mg} / \mathrm{kg} \mathrm{b.m.).}$

RESULTS: Results indicate that thymulin and thymosin alpha 1 expressively decrease TF and increase TFPI concentrations. All three thymic peptides reduce FVIIa activity, increase TFPI activity, and significantly elongate PT.
\end{abstract}

CONCLUSIONS: Thymus peptides thymulin, thymosin alpha 1 and thymosin beta 4 significantly suppress blood coagulation through the extrinsic pathway and generate a distinct tendency for hypocoagulability.

Keywords: thymulin, thymosin alpha 1, thymosin beta 4, TF, FVII, TFPI, PT

\footnotetext{
Address for correspondence:

Yuri Nyagolov

Medical University-Sofia

15 Akademik Ivan Evstratiev Geshov Blvd

1431 Sofia

e-mail:nyagolv@abv.bg
}

Received: June 26, 2017

Accepted: June 30, 2017

\section{INTRODUCTION}

The blood coagulation system is based on cascade activation of a series of enzyme reactions where proenzymes and profactors are activated by serine proteases through limited proteolysis. Activation of hemocoagulation may be performed by two basic pathways: intrinsic and extrinsic (1). The tissue factor (TF) is the principle activator of the coagulation cascade via the extrinsic pathway (2). Endothelial 
barrier injury allows TF binding to FVII/FVIIa and formation of the so-called tenase complex (TF/FVIIa). TF/FVIIa, phospholipid membranes and calcium ions catalyze conversion of plasma clotting factors IX into IXa, and X into Xa (3). The last phenomenon is considered a pivotal step of the blood coagulation process initiating the common end pathway leading to formation of thrombin and the consecutive formation of fibrin mesh (4). The regulatory subunit of the tenase complex - TF (tissue thromboplastin, CD142), is a transmembrane glycoprotein belonging to the superfamily of class II cytokine receptors. It is abundant in vascular smooth muscle cells, pericytes and adventitial fibroblasts with excessively high levels in brain, lungs, placenta, uterus and testis (5). The catalytic subunit, FVII, is a vitamin K-dependent plasma protein from the family of trypsin-like serine proteases, which is in an active form of about $1 \%$ (6). Knockout of TF and FVII genes is lethal and indicates the essential role of those elements in hemostasis (7). Tissue factor pathway inhibitor (TFPI) is the basic physiological anticoagulation mechanism of TF-initiated coagulation cascade (8) highly involved in the initiation of blood coagulation via the extrinsic pathway (9). Its molecule predominantly synthesized in vascular endothelium consists of three inhibitor Kunitztype domains (K1, K2 and $\mathrm{K} 3$ ). $\mathrm{K} 1$ binds the tenase complex (TF/FVIIa), while K2 binds FXa. The complex formed TFPI/TF/FVIIa/FXa is inactive and determines the suppressive hemocoagulation effect of TFPI (10). TFPI inhibits prothrombin activator formation responsible for conversion of prothrombin to thrombin by inactivation of FXa and FVa (11). Deviations of concentrations and activities of the components of the complex TF/FVIIa, as well as deviations of concentrations and activities of its inhibitor - TFPI, are reported in various clinical disorders (12). Prothrombin time (PT) is a basic common integral parameter of hemocoagulation (13). It is widely applied in clinical practice for estimation of blood coagulation factors via the extrinsic and the common pathways of fibrin formation (14), as well as for a screening test for deficiencies of plasma clotting factors involved in those pathways (II, V, VII, X and fibrinogen) (15). Moreover, in clinical practice, PT calculated as INR is used for estimation of the efficacy of classic oral anticoagulation therapy (16).
Though the numerous clinical and experimental studies are focused on the links between endocrine disorders and deviation of the blood coagulation status (17), the role of the thymus gland and its effects on hemostasis are relatively insufficiently defined. The existing literature data are scarce and predominantly based on pathological models with thymectomy or after application of higher doses of thymic extracts (18). Moreover, a lot of studies are focused on measurement of single hemostasis parameters leading to incomplete and controversial results (19).

The present study aims to investigate the influence of the thymus peptides thymulin, thymosin alpha 1 and thymosin beta 4 applied on intact (not thymectomized) rats, on plasma concentration of TF, free TFPI; and on the activity of plasma clotting factor VII and free TFPI, as well as on prothrombin time - an integral clinical parameter of the intrinsic pathway.

\section{MATERIALS AND METHODS}

The study was performed on 52 male Wistar strain rats. Rats weighing 200-220 g were bred under standard conditions at dark/light cycle $12 / 12 \mathrm{~h}$, with free access to standard briquette chew and water. The animals were treated according to the requirements of the European Convention for the Protection of Experimental Animals (Protection of animals used for experimental purposes, Council Directive 86/609/ EEC of November 1986) and Directive 2010/63/EU of the European Parliament and of the Council of Europe, September 2010. The rats were divided into four equal groups (13 rats in a group) - one control and three experimental and injected subcutaneously once daily in the time interval $08.00-09.00 \mathrm{~h}$ in the course of three consecutive days as follows: 1st group - with saline (the solvent of the peptides); 2 nd group - with thymulin (Sigma Aldrich, $0.4 \mathrm{mg} / \mathrm{kg}$ b.m.); 3rd group - with thymosin alpha 1 (Sigma Aldrich, $0.3 \mathrm{mg} / \mathrm{kg}$ b.m.); and the 4th group - with thymosin beta 4 (Sigma Aldrich, $0.3 \mathrm{mg} / \mathrm{kg}$ b.m.). The peptides used were in the form of a dry substance and were dissolved ex tempore. The doses used were defined on the basis of literature data, and through a preliminary analyses for determination of logarithmic dose-effect dependence. Experiments were carried out during the period of spring equinox. The ob- 
servation period duration was 72 hours. The necessary blood volume from a rat $(4.5 \mathrm{ml})$ was obtained in a plastic single usage syringe by a cardiac puncture under urethane narcosis (blood/anticoagulant ratio 9:10). Sodium citrate $(0.11 \mathrm{~mol} / \mathrm{l})$ was used as an anticoagulant. Centrifugion duration was $10 \mathrm{~min}$ utes at $3000 \mathrm{rev} / \mathrm{min}$. The supernatant was separated and stored at $4{ }^{\circ} \mathrm{C}$ in hemostatic test tubes. The coagulation parameter PT was determined not later than 2 hours by reactives of Diagnostica Stago, France on coagulometer Coag-Mate XM. The rest of the plasma was frozen and stored at $-60^{\circ} \mathrm{C}$ for the measurement of the other parameters, which were evaluated no later than 10 days after this.

TF was determined by ELISA method using a kit by American Diagnostica inc., USA. Free TFPI activity and free TFPI concentration were estimated by conventional ELISA method with kits by Diagnostica Stago, France. Factor VII activity was determined on coagulometer Coag-Mate XM by conventional kinetic coagulometric methods applied elsewhere using a test by Dade Behring, USA. At the end of the experiments the animals were autopsied and macroscopically inspected for hemorrhages. Slices from the internal organs (kidney, liver, stomach and spleen) were prepared and stained by hematoxylin-eozyne and by Weigert for fibrin for the exclusion of microhemorrhages and/or intravascular coagulation.

All data were analyzed by variation analysis, by Student-Fisher's t-test, using GraphPad Prism 5 software product. The results are presented as $\mathrm{MEAN} \pm \mathrm{SEM}$. Values of $\mathrm{p}$ less than 0.05 were considered significant.

\section{RESULTS}

Figure 1 illustrates that thymic peptides thymulin and thymosin alpha 1 significantly reduced $(\mathrm{p}<0.0001)$ TF plasma concentration from $199.7 \pm 13.60 \mathrm{ng} / \mathrm{ml}$ (control group) respectively to $95.21 \pm 14.46 \mathrm{ng} / \mathrm{ml}$ and $113.5 \pm 9.50 \mathrm{ng} / \mathrm{ml}$. Thymosin beta 4 application did not lead to significant changes of this parameter $(184.9 \pm 32.10 \mathrm{ng} / \mathrm{ml})$.

In Fig. 2 the effects of thymus peptides on free TFPI plasma concentration are presented. Thymulin and thymosin alpha 1 generated significant elevation of free TFPI plasma concentration respectively to $23.70 \pm 3.95 \mathrm{ng} / \mathrm{ml}(\mathrm{p}<0.001)$ and $16.92 \pm 1.23$ $\mathrm{ng} / \mathrm{ml}(\mathrm{p}<0.0001)$ versus the control group values

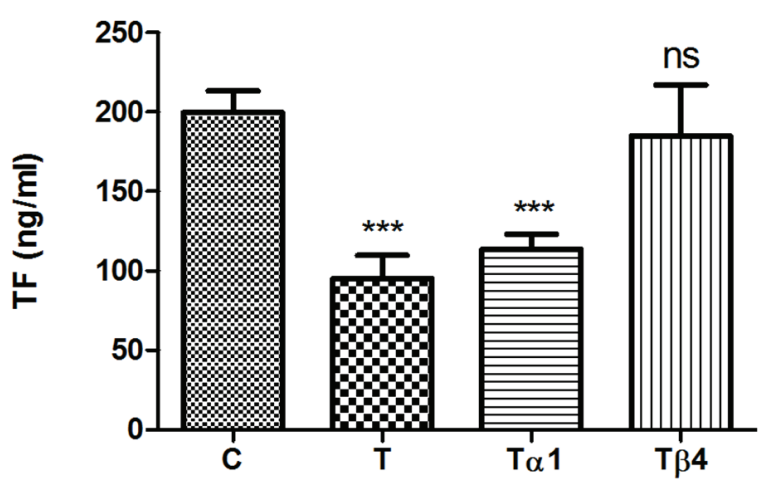

Figure 1. Effects of thymulin (0.4 mg/kg b.m.), thymosin alpha $1(0.3 \mathrm{mg} / \mathrm{kg}$ b.m.) and thymosin beta $4(0.3 \mathrm{mg} / \mathrm{kg}$ b.m.) on tissue factor (TF) plasma concentration. Data are presented as $M E A N \pm S E M, n=13$

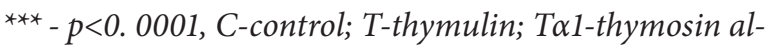
pha 1; Tß4-thymosin beta 4; ns-nonsignificant.

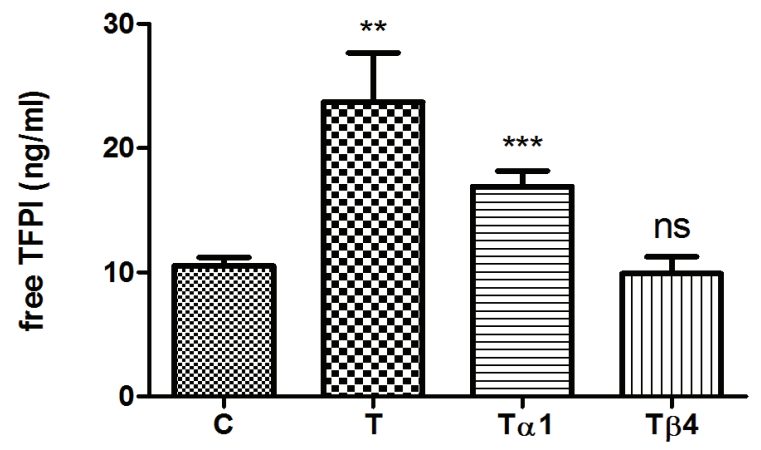

Figure 2. Effects of thymulin $(0.4 \mathrm{mg} / \mathrm{kg}$ b.m.), thymosin alpha $1(0.3 \mathrm{mg} / \mathrm{kg}$ b.m.) and thymosin beta $4(0.3 \mathrm{mg} / \mathrm{kg}$ b.m.) on tissue factor pathway inhibitor (TFPI) plasma concentration. Data are presented as MEAN $\pm S E M, n=13$

${ }^{* * *}-p<0.0001,{ }^{* *}-p<0.001, C$-control; T-thymulin;

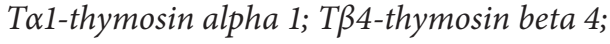
ns-nonsignificant.

$(10.54 \pm 0.65 \mathrm{ng} / \mathrm{ml})$, while the effect of thymosin beta 4 was not significant $(9.902 \pm 1.37 \mathrm{ng} / \mathrm{ml})$.

The activity of free TFPI expressed in percentage is illustrated in Fig. 3. All the three peptides increased free TFPI activity as follows: $130.3 \pm 9.49$; $\mathrm{p}<0.001$ (thymulin), 151.6 $\pm 19.24 ; \mathrm{p}<0.001$ (thymosin alpha 1) and 139.9 $\pm 20.85 ; \mathrm{p}<0.01$ (thymosin beta 4 ), compared to the control group (91.88 \pm 7.94$)$.

Factor VII activity (Fig. 4) was significantly reduced $(\mathrm{p}<0.0001)$ by the three peptides from $110.4 \pm 6.96$ (controls) to $55.09 \pm 7.04,67.91 \pm 7.63$ and $50.06 \pm 7.01$, respectively for thymulin, thymosin alpha 1 and thymosin beta 4 . 


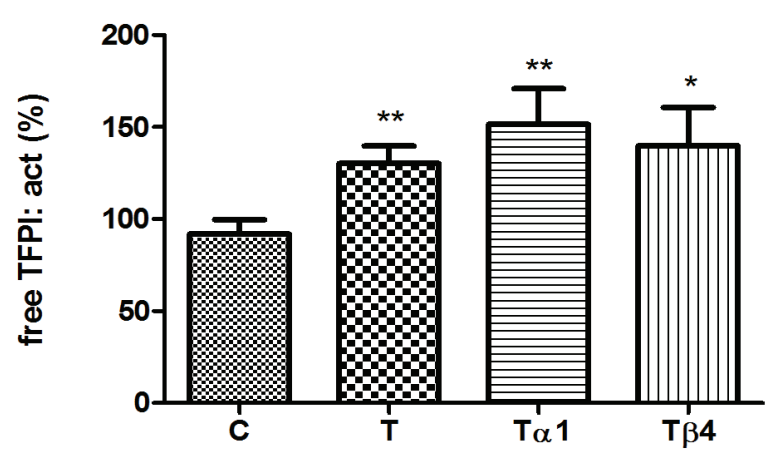

Figure 3. Effects of thymulin $(0.4 \mathrm{mg} / \mathrm{kg}$ b.m.), thymosin alpha $1(0.3 \mathrm{mg} / \mathrm{kg}$ b.m.) and thymosin beta $4(0.3 \mathrm{mg} / \mathrm{kg}$ b.m.) on tissue factor pathway inhibitor (TFPI) activity.

Data are presented as MEAN $\pm S E M, n=13$

${ }^{*}$ - $p<0.01,{ }^{* *}-p<0.001, C$-control; T-thymulin;

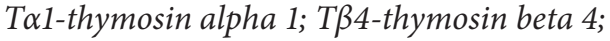
ns-nonsignificant.

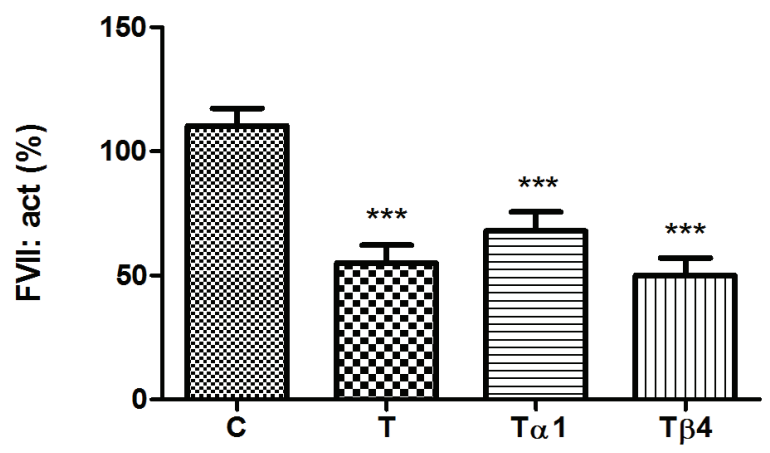

Figure 4. Effects of thymulin ( $0.4 \mathrm{mg} / \mathrm{kg}$ b.m.), thymosin alpha $1(0.3 \mathrm{mg} / \mathrm{kg} \mathrm{b.m.)} \mathrm{and} \mathrm{thymosin} \mathrm{beta} 4(0.3 \mathrm{mg} / \mathrm{kg}$ b.m.) on plasma clotting factor VII activity. Data are presented as MEAN $\pm S E M, n=13$

${ }^{* * *}$ - $p<0.0001, C$-control; T-thymulin; Ta1-thymosin alpha 1; Tß4-thymosin beta 4; ns-nonsignificant.

Figure 5 demonstrates that the peptides applied elongate PT to $21.45 \pm 2.67 \mathrm{sec}$., $\mathrm{p}<0.001$ (thymulin), $26.96 \pm 2.19$ sec., $\mathrm{p}<0.0001$ (thymosin alpha 1) and $20.99 \pm 1.50$ sec., $\mathrm{p}<0.0001$ (thymosin beta 4 ), compared to the control group ( $11.66 \pm 0.78 \mathrm{sec}$.).

Macroscopic inspections and histological studies did not indicate any signs of thrombosis or hemorrhage.

\section{DISCUSSION}

Low TF levels in clinical practice, as well as application of TF antibodies in animal experiments are associated with massive lung, brain, heart and testis hemorrhages (5). As far as inborn factor VII deficien-

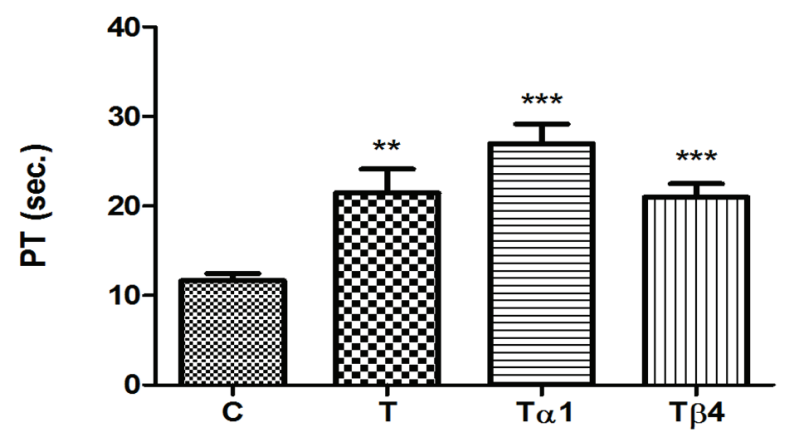

Figure 5. Effects of thymulin (0.4 $\mathrm{mg} / \mathrm{kg}$ b.m.), thymosin alpha $1(0.3 \mathrm{mg} / \mathrm{kg} \mathrm{b.m.)}$ and thymosin beta $4(0.3 \mathrm{mg} / \mathrm{kg}$ b.m.) on prothrombin time (PT). Data are presented as $M E A N \pm S E M, n=13$

${ }^{* *}$ - $p<0.001,{ }^{* * *}-p<0.0001, C$-control; T-thymulin;

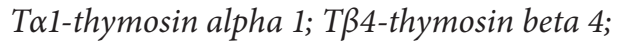
ns-nonsignificant.

cy is concerned, clinical data are rather controversial indicating both tendency of hemorrhage, as well as thrombotic incidents (6). Human recombinant factor VII is applied with a success in the therapy of severe hemorrhages.

Thymus peptides thymulin and thymosin alpha 1 reduced significantly $(\mathrm{p}<0.0001)$ TF plasma concentration in this study (Fig. 1). Tissue factor pathway inhibitor (TFPI) is postulated to suppress hemocoagulation by blockade of both the activity of the complex TF/FVIIa (20), and the prothrombinase complex (10). The clinical manifestations of elevated TFPI most commonly comprise frequent hemorrhages, menorrhagiae and life-threatening bleeding after trauma or surgical intervention (6,7). Blocking of TFPI activity recovers the process of thrombin formation via the extrinsic pathway and normalizes the hemostatic process. Pharmacological agents suppressing TFPI activity are reported to be applied in hemophilia treatment (21). In this study thymulin and thymosin alpha 1 elevated free TFPI concentration, while thymosin beta 4 did not impact significantly this parameter (Fig. 2). TFPI activity was considerably increased by the three thymic peptides (Fig. 3). Having in mind the mechanism(s) of the effect of TFPI, one could easily explain the shifts of the activity of plasma clotting factor VIIa (Fig. 4), which is in harmony with TFPI significantly decreased $(\mathrm{p}<0.0001)$ by the three peptides. These data allow the presumption, though speculatively, that a lower rate of formation of the tenase complex TF/FVIIa 
is involved in the initial phase of blood coagulation via the extrinsic pathway. Upper result analysis establishes that thymus peptides thymulin, thymosin alpha 1 and thymosin beta 4 undoubtedly generate a noticeable tendency of hypocoagulability. PT is a parameter highly informative about the integrity of the coagulation process via the extrinsic and common pathway cascades (5). Data in Figure 5 indicating significant lengthening of PT by thymulin $(\mathrm{p}<0.001)$, thymosin alpha 1 and thymosin beta $4(\mathrm{p}<0.0001)$ are in good harmony with the changes of the other parameters studied, supporting the tendency of reduced coagulability.

\section{CONCLUSION}

The results of this study illustrate that thymic peptides thymulin, thymosin alpha 1 and thymosin beta 4 exert substantial effect on the processes involved in the initiating mechanism of blood coagulation via the extrinsic pathway. Thymulin and thymosin alpha 1 significantly reduce TF concentration, at the same time elevate the plasma concentration of its principal inhibitor - TFPI, while thymosin beta 4 does not influence these parameters. The three thymic peptides increase TFPI activity and decrease FVIIa activity and elongate PT. These data evidence that thymulin, thymosin alpha 1 and thymosin beta 4 applied on intact rats inhibit the trigger mechanism of hemocoagulation via the extrinsic pathway creating a distinct tendency of hypocoagulability.

\section{REFERENCES}

1. Palta S, Saroa R, Palta A. Overview of the coagulation system. Indian J Anaesth. 2014;58 (5):515-23. doi: 10.4103/0019-5049.144643

2. Morrissey JH. Tissue factor: a key molecule in hemostatic and nonhemostatic systems. Int J Hematol. 2004;79(2):103-8. doi: 10.1532/IJH97.03167

3. Mackman N. Role of tissue factor in hemostasis, thrombosis, and vascular development. Arterioscler Thromb Vasc Biol. 2004;24(6):1015-1022. doi: 10.1161/01.ATV.0000130465.23430.74

4. Edgington TS, Dickinson CD, Ruf W. The structural basis of function of the TF. VIIa complex in the cellular initiation of coagulation. Thromb Haemost. 1997;78(1):401-5.

5. Mackman N. The role of tissue factor and factor VIIa in hemostasis. Anes- th Analg. 2009;108(5):1447-52. doi: 10.1213/ ane.0b013e31819bceb1

6. Gajsiewicz JM, Morrissey JH. Structure-Function Relationship of the Interaction between Tissue Factor and Factor VIIa. Semin Thromb Hemost. 2015;41(7):682-90. doi: 10.1055/s-0035-1564044

7. Rosen ED, Xu H, Liang Z, Martin JA, Suckow M, Castellino FJ. Generation of genetically-altered mice producing very low levels of coagulation factor VII. Thromb Haemost. 2005;94(3):493-7. doi: 10.1160/TH05-05-0337

8. Maroney SA, Mast AE. New insights into the biology of tissue factor pathway inhibitor. J Thromb Haemost. 2015;13(1):200-7. doi: 10.1111/jth.12897

9. Lasne D, Jude B, Susen S. From normal to pathological hemostasis. Can J Anaesth. 2006;53 (Suppl 2):2-11. doi:10.1007/BF03022247

10. Mast AE. Tissue Factor Pathway Inhibitor: Multiple Anticoagulant Activities for a Single Protein. Arterioscler Thromb Vasc Biol. 2016;36(1):9-14. doi: 10.1161/ATVBAHA.115.305996

11. Wood JP, Bunce MW, Maroney SA, Tracy PB, Camire RM, Mast AE. Tissue factor pathway inhibitor-alpha inhibits prothrombinase during the initiation of blood coagulation. Proc Natl Acad Sci U S A. 2013;110(44):17838-43. doi: 10.1073/ pnas. 1310444110

12. Franchini M, Lippi G, Manzato F, Vescovi P, Targher G. Hemostatic abnormalities in endocrine and metabolic disorders. Eur J Endocrinol. 2010;162(3):439-51. doi: 10.1530/EJE-09-0958

13. Mann KG. Biochemistry and physiology of blood coagulation. Thromb Haemost 1999;82(2):165-174.

14. Bajaj SP, Joist JH. New insights into how blood clots: implications for the use of APTT and PT as coagulation screening tests and in monitoring of anticoagulant therapy. Semin Thromb Hemost 1999;25(4):407-418. doi: 10.1055/s-2007-994943

15. Genecov DG, Por YC, Barcelo CR, Salyer KE, Mulne AF, Morad AB. Preoperative screening for coagulopathy using prothrombin time and partial thromboplastin time in patients requiring primary cranial vault remodeling. Plast Reconstr Surg. 2005;116(2):389-94. doi: 10.1097/01. prs.0000172760.79803.68

16. Chee YL, Greaves M. Role of coagulation testing in predicting bleeding risk. Hematol J. 2003;4(6):3738. doi: 10.1038/sj.thj.6200306 
17. Franchini M, Vescovi PP, Manzato F, Favaloro EJ. Hormones, endocrine disorders, and hemostasis. Semin Thromb Hemost. 2011;37(1):3-5. doi: 10.1055/s-0030-1270064

18. Liapina LA, Pastorova VE, Kudriashov BA, Zazhireì VD, Sokolova EA, Lishvits VA et al. The action of timoptin peptides on the hemostatic system. Izv Akad Nauk SSSR Biol. 1990;3:377-82.

19. Andreenko GV, Ashmarin IP, Zazhireĭ VD, Livshits VA, Serebriakova TN, Podorol'skaia LV. The effect of thymoptin on enzymatic fibrinolysis. Vopr Med Khim. 1989;35(5):108-11.

20. Ellery PE, Adams MJ. Tissue factor pathway inhibitor: then and now. Semin Thromb Hemost. 2014;40(8):881-6. doi: 10.1055/s-0034-1395153

21. Chowdary P, Lethagen S, Friedrich U, Brand B, Hay C, Abdul Karim F et al. Safety and pharmacokinetics of anti-TFPI antibody (concizumab) in healthy volunteers and patients with hemophilia: a randomized first human dose trial. J Thromb Haemost. 2015;13(5):743-54. doi: 10.1111/jth.12864 